\title{
Sulfonated carbon black-based composite membranes for fuel cell applications
}

\author{
HACER DOĞAN, EMEL YILDIZ, METIN KAYA ${ }^{\dagger}$ and TÜLAY Y INAN* \\ TUBITAK, Marmara Research Centre, Chemistry Institute, 41470 Gebze-Kocaeli, Turkey \\ †Türk Demirdöküm Fabrikalari A.Ş., 4 Eylül Mah. İsmet İnönü, Cad. No: 245, Bozüyụk’’B̉ilecik, Turkey
}

MS received 11 October 2011; revised 9 May 2012

\begin{abstract}
Two different commercial grade carbon black samples, Cabot Regal 400R (C1) and Cabot Mogul L (C2), were sulfonated with diazonium salt of sulfanilic acid. The resultant sulfonated carbon black samples (S-C) were characterized by Fourier transform infrared spectroscopy (FTIR) and thermal gravimetric analysis (TGA). Composite membranes were then prepared using S-C as fillers and sulfonated poly(ether ether ketone) (SPEEK) as polymer matrix with three different sulfonation degrees $(\mathrm{DS}=60,70$ and $82 \%)$. Structure and properties of the composite membranes were characterized by FTIR, TGA, scanning electron microscopy, proton conduction, water uptake, ion exchange capacity and chemical stability. Incorporation of S-C particles above 0.25 wt $\%$ caused decrease in chemical stability. Pristine and composite membranes prepared from SPEEK82 decomposed completely in $<1 \mathrm{~h}$, which is undesirable for fuel cell applications. SPEEK60 membrane having wt\% of $0.25-0.5$ with $\mathrm{S}-\mathrm{C}$ particles led to higher proton conductivity than that of pristine membrane. No positive effect was observed on the properties of the composite membranes with the addition of $\mathrm{S}-\mathrm{C}$ particles at high concentrations due to the agglomeration problems and decrease in the content of conductive polymer matrix.
\end{abstract}

Keywords. Fuel cell; sulfonated carbon black; SPEEK; proton conductive membranes.

\section{Introduction}

Sulfonated poly(ether ether ketone) (SPEEK) polymers are very promising materials for membranes in the fuel cell applications owing to their good thermal stability, mechanical strength and ion exchange capacity (IEC) (Kerres et al 1999; Xing et al 2004). The proton conductivity, swelling degree and dissolvability of SPEEK polymers strongly depend on sulfonation degree (DS). SPEEKs with high and low DS dissolve in water at room- and high-temperatures, respectively. After $80 \%$ of DS membranes start to swell, which is undesirable for fuel cell applications. To overcome these drawbacks and to improve SPEEK membrane properties, some materials being both hydrophilic and proton conducting have been incorporated into SPEEK polymer matrix. Inorganic materials like zirconium phosphate, sulfophenyl-phosphonate, heteropolyacid, layered silicates (such as laponite, modified montmorillonite), zeolites, boron phosphate silicates and functionalized silicates, metal oxides and sulfated zirconia have been embedded into SPEEK membranes (Herring 2006).

Recently, carbon nanotubes (CNTs) have attracted particular interest due to their exceptional mechanical properties, low density and high aspect ratio. For fuel cell applications, CNTs (Liu et al 2006; Thomassin et al 2007; Wang et al 2008) and functionalized CNTs (Kannan et al 2008) were

\footnotetext{
*Author for correspondence (Tulay.Inan@mam.gov.tr)
}

incorporated into a Nafion ${ }^{\circledR}$ matrix. CNTs reinforced Nafion composite membranes, with the addition of a small amount of CNTs (1 wt \%), showed excellent mechanical strength and fuel cell performance compared with the native Nafion ${ }^{\circledR}$ membrane. Thomassin et al (2007) depicted that multi-walled CNTs dispersed by melt-extrusion within Nafion ${ }^{\circledR}$ membranes decreased methanol permeability by $\sim 60 \%$ without any decrease in ionic conductivity. Kannan et al (2008) reported that the addition of CNTs functionalized with sulfonic acid groups into Nafion ${ }^{\circledR}$ membranes could improve the proton conductivity due to the increased sulfonic acid content and decreased methanol permeability. It was also observed (Barroso-Bujans et al 2008) that the addition of sulfonated CNTs $(\sim 5 \mathrm{wt} \%)$ to ethylene propylene diene terpolymer rubber membrane could increase the proton conductivity of polymeric membranes.

It was shown that sulfonic acid functionalized CNTs/ SPEEK composite membrane prepared for direct methanol fuel cell applications improved the mechanical properties in terms of tensile strength and tougness when compared with neat SPEEK membrane, CNT-SPEEK composite membrane contained more uniform and smaller ion clusters, which results in an increase in ionic conductivity and a decrease in methanol permeability (Joo et al 2008).

In the present study, carbon black that is the most common carbon form was sulfonated with diazonium salt of sulfanilic acid for the first time. Diazonium salt of sulfanilic acid was prepared by the reaction of sulfanilic acid with 
sodium nitride and then attached onto two different carbon black particles (Cabot Regal 400R (C1) and Cabot Mogul L (C2)). Composite membranes were then prepared using sulfonated carbon black particles ( $\mathrm{S}-\mathrm{C} 1$ and $\mathrm{S}-\mathrm{C} 2$ ) as fillers and SPEEK as polymer matrix with three DS (60, 70 and 82\%). Structure and properties of the composite membranes were characterized by Fourier transform infrared spectroscopy (FTIR), thermal gravimetric analysis (TGA), scanning electron microscopy (SEM), proton conduction, water uptake, ion exchange capacity (IEC) and chemical stability. Composite membranes were found to be appropriate for fuel cell applications.

\section{Experimental}

\subsection{Materials}

Polyether ether ketone (PEEK) 450 PF obtained in powder form (particle size of $25 \mu \mathrm{m}$ ) from Victrex was dried in vacuum at $100^{\circ} \mathrm{C}$ overnight. Sulfuric acid (95-97 wt \%), hydrogen peroxide $\left(\mathrm{H}_{2} \mathrm{O}_{2}\right)$ and dimethylacetamide (DMAc, for synthesis) were obtained from Fluka. Sulfanilic acid and sodium nitride were received from Aldrich. Carbon black samples were obtained from Cabot Corporation.

\subsection{Sulfonation of PEEK}

PEEK was sulfonated by using concentrated sulfuric acid (conc. $\mathrm{H}_{2} \mathrm{SO}_{4}$ ) following the same procedure reported by Zaidi (2003). $5 \mathrm{~g}$ dried PEEK was dissolved completely in $100 \mathrm{~mL}$ concentrated sulfuric acid (95-97\%) under nitrogen at $25^{\circ} \mathrm{C}$ by strong mechanical agitation, at least $800 \mathrm{rpm}$, to maintain a homogenous reaction media. Later, the temperature was increased to the desired reaction temperature. The desired sulfonation degrees of 60,70 and $82 \%$ were achieved at different reaction times and then the reaction solution was gradually precipitated into cold deionized water under agitation. The precipitate was washed with deionized water and filtered several times until the $\mathrm{pH}$ value was approximately between 6 and 7. Sulfonated polymer samples were dried in vacuum at room temperature for $12 \mathrm{~h}$ and then at $60{ }^{\circ} \mathrm{C}$ for another $12 \mathrm{~h}$. SPEEKs with 60, 70 and $82 \%$ DS were used in the membrane preparation. The produced sulfonated PEEK polymer was denoted as SPEEKX, where $\mathrm{X}$ represents sulfonation degree of SPEEK.

\subsection{Sulfonation of carbon black}

$11.3 \mathrm{~g}$ sulfanilic acid was dissolved in the solution containing $18.5 \mathrm{~mL} \mathrm{HCl}, 10 \mathrm{~mL}$ acetone and $90 \mathrm{~mL}$ deionized water by continuous stirring. Temperature of the reaction was kept at $2{ }^{\circ} \mathrm{C}$ by means of Haake laboratory water circulator. Sodium nitrite $(4.8 \mathrm{~g})$ dissolved in water was added to the reaction mixture drop by drop with the help of a dropping funnel. The reaction was continued until the mixture is completely dissolved. Then, carbon black sample $(82 \mathrm{~g})$ was added to the reaction mixture at $2{ }^{\circ} \mathrm{C}$ and mixed for $10 \mathrm{~h}$. At the end of the reaction, modified carbon black sample was separated by filtration. The resulting product was washed with deionized water at room temperature until $\mathrm{pH}$ of the filtrate became neutral. After washing with deionized water, the product was washed with acetone and dried at a temperature of $105{ }^{\circ} \mathrm{C}$ in a vacuum oven. The modified carbon black samples were ground and sieved to obtain particles with size of 20-30 meshes.

\subsection{Membrane preparation}

Membranes were prepared by casting 20\% DMAc solutions of SPEEK containing $\mathrm{S}-\mathrm{C}$ particles on a clean glass plate. Membranes were dried in vacuum for $8 \mathrm{~h}$ at $30-60^{\circ} \mathrm{C}$ and for another $15 \mathrm{~h}$ at $60-80{ }^{\circ} \mathrm{C}$. Then, membranes were soaked and kept in deionized water until testing. The membranes were analysed by headspace-gas chromatography/mass spectrometry and nuclear magnetic resonance that assured no solvent residue remained in the membranes. The membrane thickness was measured at dry state using a digital micrometer. The thickness of prepared membranes ranged from 80 to $100 \mu \mathrm{m}$.

\subsection{Characterization of $S-C$ particles and composite membranes}

2.5a Morphological characterization: Membrane morphology was investigated by using SEM (JEOL JSM$6335 \mathrm{~F}$ ). Moreover, membranes prepared by metallographic techniques were investigated with Nikon ${ }^{\mathrm{TM}}$ L 150 optical microscope.

2.5b TGA studies: Thermal stability of the membranes and $\mathrm{S}-\mathrm{C}$ particles were determined by using Perkin Elmer PYRIS 1 TGA. Membrane samples were heated under nitrogen atmosphere up to $150{ }^{\circ} \mathrm{C}$ and kept at this temperature for half an hour to remove the moisture completely. The samples were cooled down to $80^{\circ} \mathrm{C}$ and then re-heated up to $900{ }^{\circ} \mathrm{C}$ with a heating rate of $10^{\circ} \mathrm{C} / \mathrm{min}$.

2.5c Differential scanning calorimeter (DSC): DSC analyses were performed with Perkin Elmer Jade DSC at a heating rate of $10^{\circ} \mathrm{C} / \mathrm{min}$ under nitrogen atmosphere. All data were collected from a second heating cycle and glass transition temperatures $\left(T_{\mathrm{g}}\right)$ were calculated as a midpoint of thermogram.

2.5d FTIR studies: FTIR spectra were recorded for membranes using Perkin Elmer Pyris 1 FTIR spectrophotometer. Membrane and carbon black samples were prepared by making $\mathrm{KBr}$ pellets. 


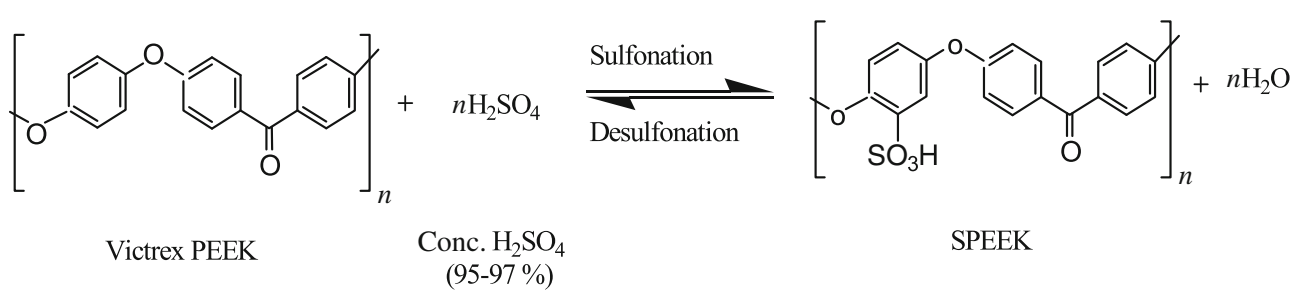

Figure 1. Schematic representation of PEEK sulfonation reaction.

2.5e Water uptake: Water uptake value (WU\%) was determined according to ASTM D 570-98. SPEEK composite membranes were conditioned in an oven at $105{ }^{\circ} \mathrm{C}$ for $1 \mathrm{~h}$ and then at $50{ }^{\circ} \mathrm{C}$ for $24 \mathrm{~h}$. Conditioned samples were cooled to room temperature in desiccators, immediately weighed $\left(W_{\text {dry }}\right)$ and then immersed in water at room temperature for $24 \mathrm{~h}$. Membranes were removed from water, wiped free of moisture with dry cloth and then weighed immediately $\left(W_{\text {wet }}\right)$ again. Percentage increase in weight during immersion was calculated as follows:

$$
\mathrm{WU}(\%)=\left(W_{\text {wet }}-W_{\text {dry }}\right) \times 100 / W_{\text {dry }} .
$$

2.5f IEC: IEC of SPEEK composite membranes was determined quantitatively by titration method according to the previously described procedure (Drioli et al 2004). 0.2$0.3 \mathrm{~g}$ of dried samples was immersed into $50 \mathrm{~mL}$ of saturated $\mathrm{NaCl}$ solution at $50{ }^{\circ} \mathrm{C}$ for $48 \mathrm{~h}$ to exchange $\mathrm{H}^{+}$with $\mathrm{Na}^{+}$. The polymer solution containing released $\mathrm{H}^{+}$was titrated with $0 \cdot 1 \mathrm{~N} \mathrm{NaOH}$ solution by using bromothymol blue as an indicator.

IEC values for both sulfonated polymers $\left(E_{\mathrm{p}}\right)$ and membranes $\left(E_{\mathrm{m}}\right)$ were calculated by using the following equation:

$$
\mathrm{IEC}=\frac{V_{\mathrm{NaOH}} \times N_{\mathrm{NaOH}} \times F_{\mathrm{NaOH}}}{W_{\mathrm{p}}},
$$

where $V_{\mathrm{NaOH}}$ is the titrated volume of $\mathrm{NaOH}$ solution (L), $N_{\mathrm{NaOH}}$ the normality of $\mathrm{NaOH}$ solution and $W_{\mathrm{p}}$ the dried weight of polymer or membrane $(\mathrm{g})$.

DS (\%) for SPEEK was calculated by using the following equation:

$$
\operatorname{DS}(\%)=\frac{288 \times \mathrm{IEC}}{1000-102 \times \mathrm{IEC}} \times 100 .
$$

$2.5 \mathrm{~g}$ Proton conductivity: The proton conductivity of SPEEK composite membranes was determined by using BT-512 BekkTech membrane test system at varying relative humidity (30-100\%) for the fuel cell working temperatures of $80{ }^{\circ} \mathrm{C}$.

2.5h Chemical stability tests: Fenton test (chemical stability test) was carried out according to the procedure described by Zhang and Mukerjee (2006). Test specimens were cut into $2 \times 2 \mathrm{~cm}$ pieces. All samples were dried in vacuum at $68^{\circ} \mathrm{C}$ for $12 \mathrm{~h}$ before test. Well-dried membrane
Table 1. Properties of carbon black samples (Rositani et al 1987; Girard et al 2006).

\begin{tabular}{lcc}
\hline & C-1 (Regal 400R) & C-2 (Mogul L) \\
\hline Surface area $\left(\mathrm{m}^{2} \mathrm{~g}^{-1}\right)$ & 86 & 138 \\
Pore volume $\left(\mathrm{cm}^{3} 10^{-2} \mathrm{~g}^{-1}\right)$ & 70 & 55 \\
Elemental analysis $(\%)$ & & \\
$\mathrm{C}$ & 95.9 & 94.9 \\
$\mathrm{H}$ & 0.5 & 0.5 \\
$\mathrm{~S}$ & 0.9 & 1.0 \\
O & 1.5 & 3.0 \\
Basis ash $(\%)$ & 0.9 & 0.5 \\
\hline
\end{tabular}

samples were treated in $3 \mathrm{wt} \% \mathrm{H}_{2} \mathrm{O}_{2}$ which contained $4 \mathrm{ppm}$ $\mathrm{Fe}^{+2}$. Then the time rupture or weight loss for a certain time was reported.

\section{Results and discussion}

\subsection{Sulfonation of PEEK}

Different sulfonation agents (conc. sulfuric acid, chlorosulphonic acid and fumed sulfuric acid) have been used in previous works for PEEK sulfonation (Fu et al 2008; Gosalawit et al 2008). In this study, an easy and relatively cheap method for PEEK sulfonation was applied using conc. sulfuric acid (95-97\%) and sulfonation reaction was depicted in figure 1. It is known that DS can be controlled by changing the reaction time, acid concentration and temperature, whereby sulfonation range of 30-100\% can be obtained (Zaidi 2003). PEEK was sulfonated for different reaction times ranging from 3 to $112 \mathrm{~h}$ and temperatures from 23 to $60{ }^{\circ} \mathrm{C}$ to produce polymers of various DS. In this study, SPEEK with sulfonation degree of 60 and $70 \%$ was prepared at a temperature of $60{ }^{\circ} \mathrm{C}$ for 3 and $4 \mathrm{~h}$, respectively.

\subsection{Sulfonation of carbon black}

Carbon black is widely used as filler in elastomers, plastics and paints to modify mechanical, electrical and optical properties of materials. Surface properties of carbon play an important role in the interaction of carbon with its surrounding environment (Lakshmi et al 2006). Carbon black is basically a hydrophobic solid and its surface characteristics can be modified by oxidation. It is well known that different 
carbons have different surface functionalities depending on nature and mode of formation of carbon samples. As shown in table 1 , commercial carbon blacks contain appreciable amounts of chemically combined hydrogen, oxygen

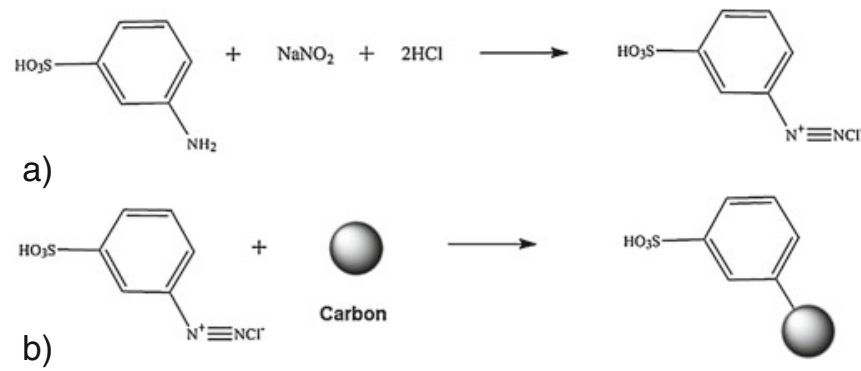

Figure 2. Schematic representation of formation of diazonium salt (a) and binding of diazonium salt onto carbon surface (b). and sulfur. C-2 coded carbon black has higher amount of oxygen $(3.0 \%)$ element and as a result, higher external surface area $\left(138 \mathrm{~m}^{2} / \mathrm{g}\right)$ than $\mathrm{C}-1$ coded carbon black. In this study, two different carbon black samples were sulfonated and sulfonation of carbon blacks decreased the hydrophobic characteristics of carbon black and it was used in hydrophobic and hydrophilic groups bearing SPEEK matrix for the fuel cell system for low temperature applications.

The functionalization of carbon black surfaces by organic materials is an attractive approach for designing novel welldefined and robust interfaces for numerous applications such as molecular electronics, photovoltaic conversion and chemical/biological sensing (Girard et al 2006). Functional groups such as $-\mathrm{COOH},-\mathrm{SO}_{3} \mathrm{H}$ and $-\mathrm{N}\left(\mathrm{C}_{2} \mathrm{H}_{5}\right)_{2}$ can be bound to the carbon black particles covalently. In this study, functionalization of carbon black was performed by covalent attachment of sulfonic acid containing diazonium salt

a)
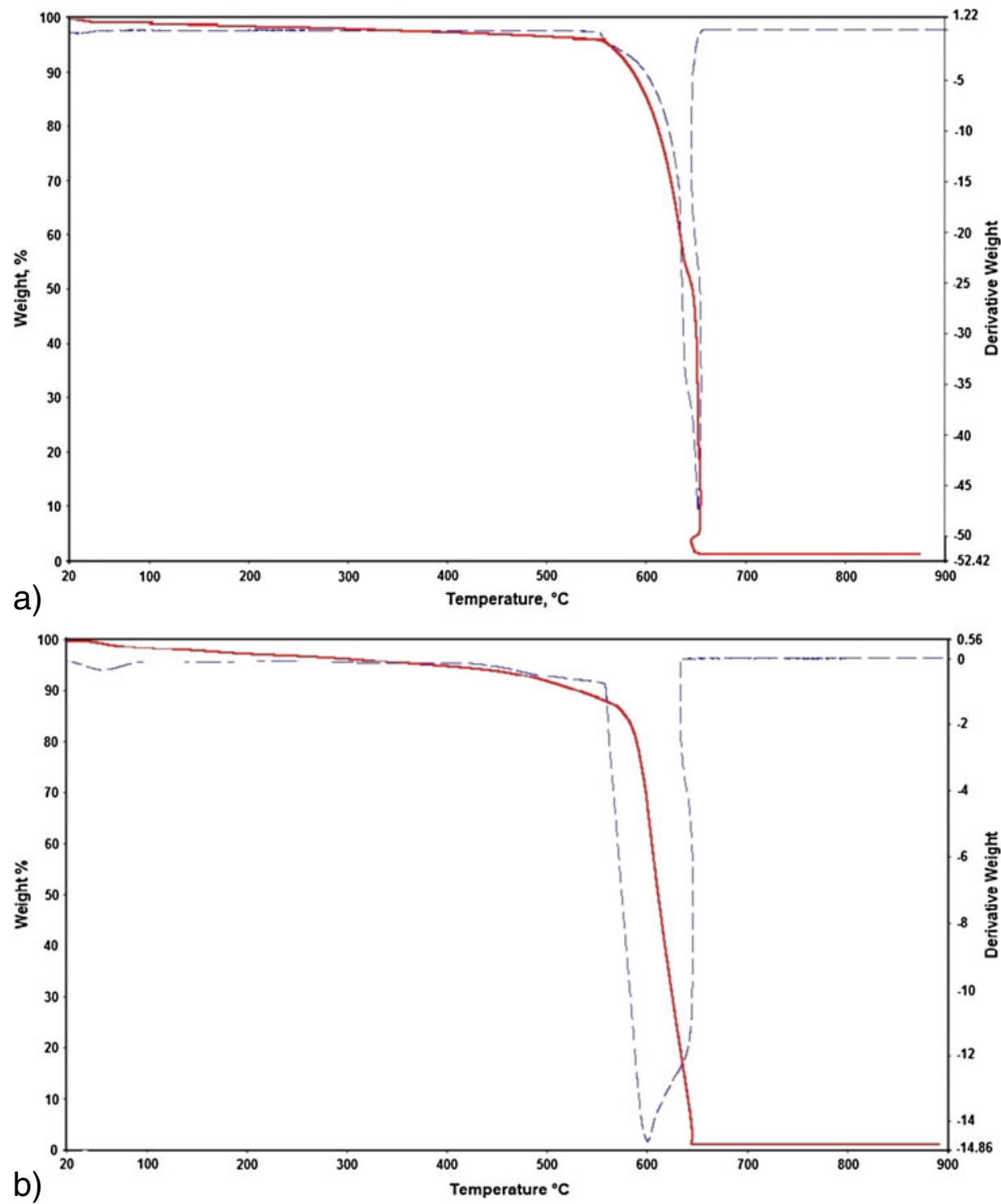

Figure 3. TGA thermograms of (a) pristine carbon samples and (b) sulfonated carbon samples (S-C1). 
(figure 2). Diazonium salt was prepared by reacting sodium nitrite with sulfanilic acid. The reaction steps are: (i) formation of nitrous acid from sodium nitride in the presence of $\mathrm{HCl}$, (ii) formation of nitrosonium ion (iii) formation of diazonium ion and (iv) bonding of diazonium salt on the carbon surface.

Thermogravimetric analysis was used to determine the degree of functionalization of carbon black samples. TGA profiles obtained in a nitrogen atmosphere of both pristine and treated carbon black samples are shown in figure 3 . Pristine carbon black remained thermally stable until almost $550{ }^{\circ} \mathrm{C}$. Then, rapid weight loss was observed between 550 and $700{ }^{\circ} \mathrm{C}$. The weight loss until $550{ }^{\circ} \mathrm{C}$ for sulfonated carbon black indicates that decrease in the weight of sulfonated carbon black can be attributed to thermal decomposition of $\mathrm{SO}_{3} \mathrm{H}$ groups (table 2). The weight loss until $550^{\circ} \mathrm{C}$ suggests that the content of $\mathrm{SO}_{3} \mathrm{H}$ groups on $\mathrm{C}-1$ is higher than that of $\mathrm{SO}_{3} \mathrm{H}$ groups on $\mathrm{C}-2$, although it has lower surface area than $\mathrm{C}-2$. We speculated that this was due to the higher pore volume of $\mathrm{C}-1$.

FTIR spectra of pure and sulfonated carbon black samples are shown in figure 4 . The broad peak at around $3435 \mathrm{~cm}^{-1}$ is

Table 2. Thermal characteristics of unmodified and modified carbon black samples.

\begin{tabular}{lcccc}
\hline & \multicolumn{4}{c}{ Weight losses (wt\%) } \\
\cline { 2 - 5 } & $0-150{ }^{\circ} \mathrm{C}$ & $150-550{ }^{\circ} \mathrm{C}$ & $550-670{ }^{\circ} \mathrm{C}$ & $670-900{ }^{\circ} \mathrm{C}$ \\
\hline $\mathrm{C} 1$ & $1 \cdot 7$ & $2 \cdot 6$ & 94.2 & 1.5 \\
$\mathrm{C} 2$ & 1.4 & $3 \cdot 3$ & $94 \cdot 1$ & 1.2 \\
$\mathrm{~S}-\mathrm{C} 1$ & $2 \cdot 1$ & $9 \cdot 1$ & 87.3 & 1.5 \\
S-C2 & $3 \cdot 1$ & 4.8 & $90 \cdot 8$ & 1.3 \\
\hline
\end{tabular}

attributed to $\mathrm{O}-\mathrm{H}$ stretching from $\mathrm{H}_{2} \mathrm{O}$ or phenol groups. The bands at $\sim 2625$ and $\sim 2830 \mathrm{~cm}^{-1}$ are ascribed to asymmetric and symmetric $\mathrm{CH}$ vibrations in $\mathrm{CH}_{3}$ and $\mathrm{CH}_{2}$ groups (Rositani et al 1987). The absorption band at $1628 \mathrm{~cm}^{-1}$ could be attributed to highly conjugated $\mathrm{CO}$ in quinone configuration. The aromatic hydrogen stretching is observed at around $620 \mathrm{~cm}^{-1}$. For sulfonated carbon black, additional peaks at 1175, 1050 (aromatic $\mathrm{C}-\mathrm{C}$ stretching) and $700 \mathrm{~cm}^{-1}$ ( $\mathrm{S}-\mathrm{O}$ stretching) which are absent in pristine carbon black, indicate the presence of $\mathrm{S}=\mathrm{O}$. This observation clearly indicates that the surface modification of carbon black was successfully achieved by sulfonic acid.

\subsection{Composite membrane characterization}

Photograph of the composite membrane containing carbon black particles is given in figure 5 .

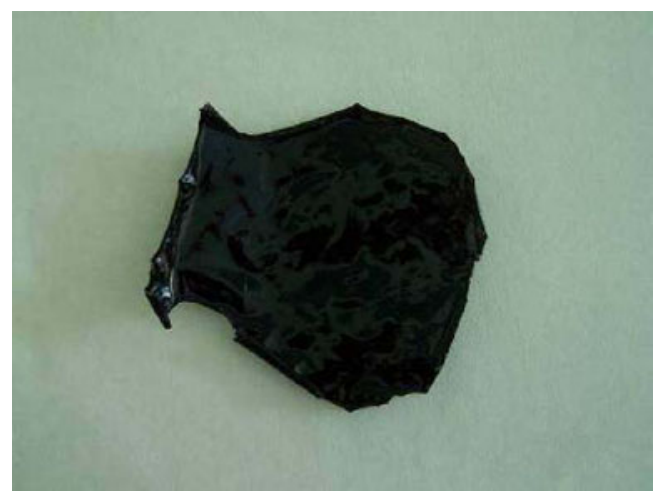

Figure 5. Photograph of SPEEK-sulfonated carbon black composite membrane.

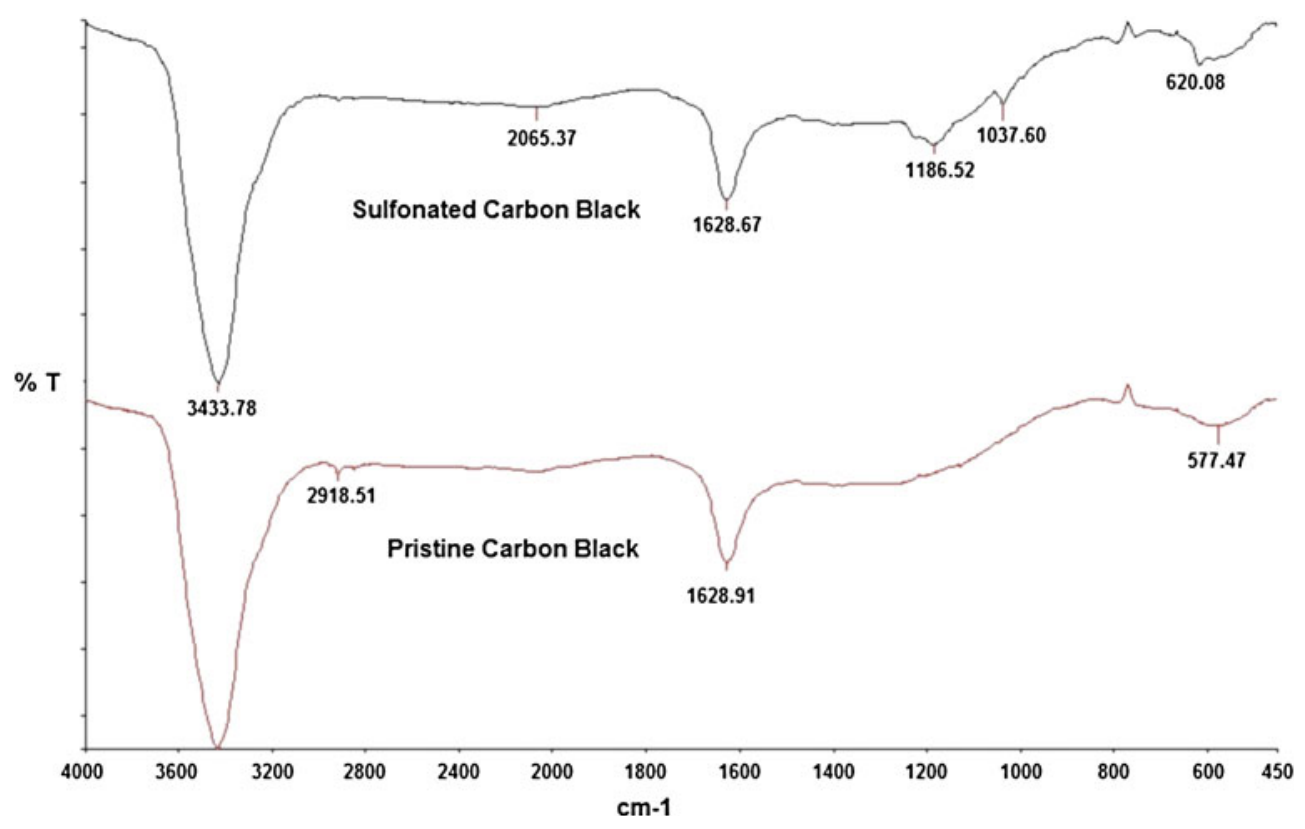

Figure 4. FTIR spectra of (a) pristine carbon black samples and (b) sulfonated carbon black samples. 
3.3a Membrane morphology: The morphology of SPEEK composite membranes containing $\mathrm{S}-\mathrm{C}$ particles was studied by SEM and optical microscope. The cross-sectional images and optical micrographs of SPEEK60 and SPEEK70 membranes containing $\mathrm{S}-\mathrm{C}$ particles ranging from 0.25 to $3 \%$ are given in figures 6 and 7 , respectively. S-C particles seem to be homogeneously dispersed within SPEEK matrix, having wt $\%$ of 0.25 and 0.5 . The addition of more than $0.5 \mathrm{wt} \% \mathrm{~S}-\mathrm{C}$ particles tend to concentrate in certain regions of SPEEK matrix by creating large agglomerates. Substantial increase in density of the agglomerates occurred by increasing the amount of $\mathrm{S}-\mathrm{C}$ particles. This behaviour was observed for SPEEK70 matrices more predominantly as shown in optical micrographs as circles (figure 7). S-C content of $3 \mathrm{wt} \%$ in SPEEK70 also gave larger agglomerates than SPEEK60. Water uptake and IEC results of SPEEK70 based membranes support this behaviour, having higher values than that of SPEEK60 based membranes. Use of S-C particles having different properties almost resulted in similar behaviours in SPEEK membranes, however, more separated regions were observed for SPEEK70/S-C1 composite membrane because of the properties of $\mathrm{C} 1$. It is known that carbon particles interact easily with one another due to the presence of surface
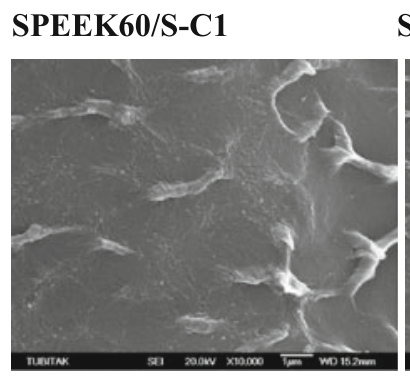

$0.25 \%$
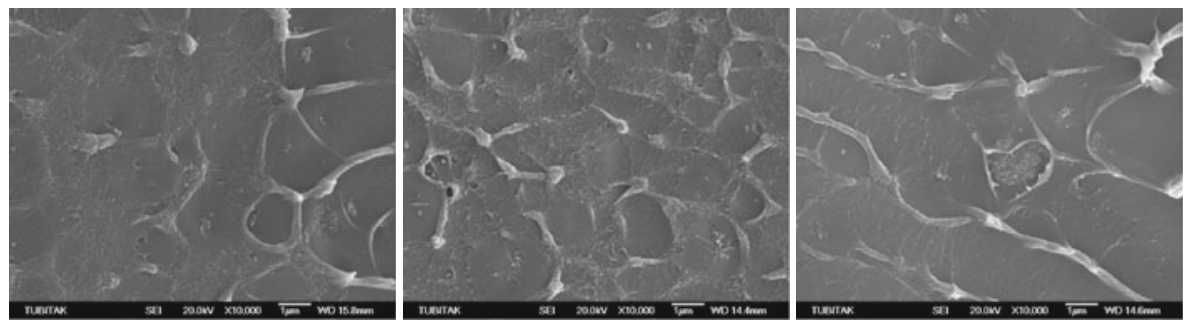

$0.5 \%$
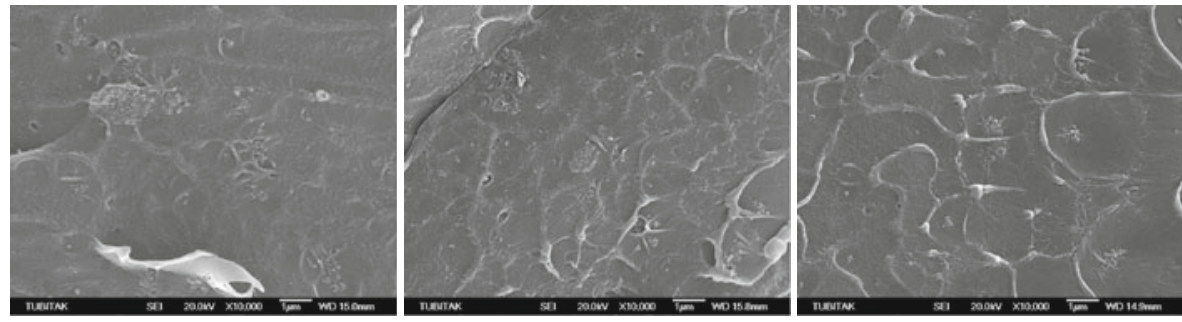

$1 \%$
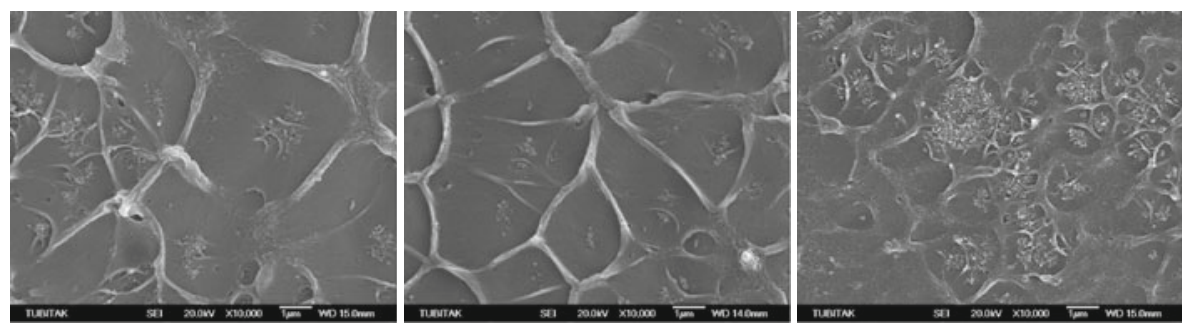

$3 \%$

Figure 6. Cross-sectional SEM photographs of SPEEK-sulfonated carbon black composite membranes with different amounts of sulfonated carbon black particles ( $\mathrm{S}-\mathrm{C} 1$ and $\mathrm{S}-\mathrm{C} 2$ ). 


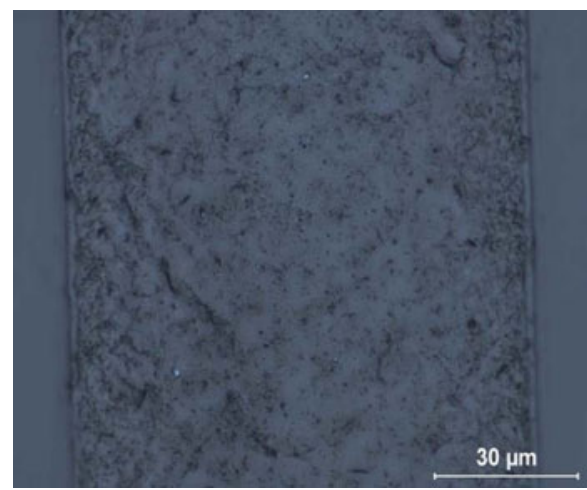

SPEEK60/0.25\% S-C1

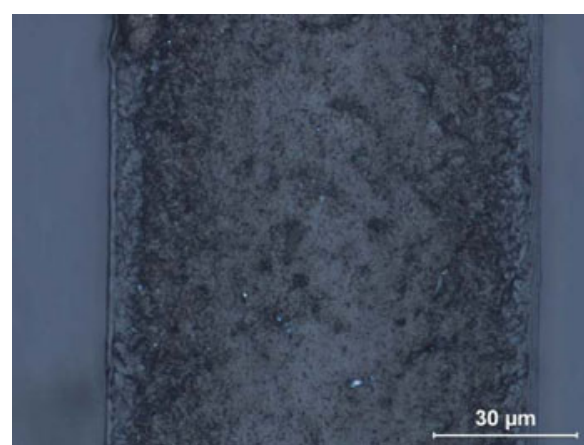

SPEEK $70 / 0.25 \%$ S-C1

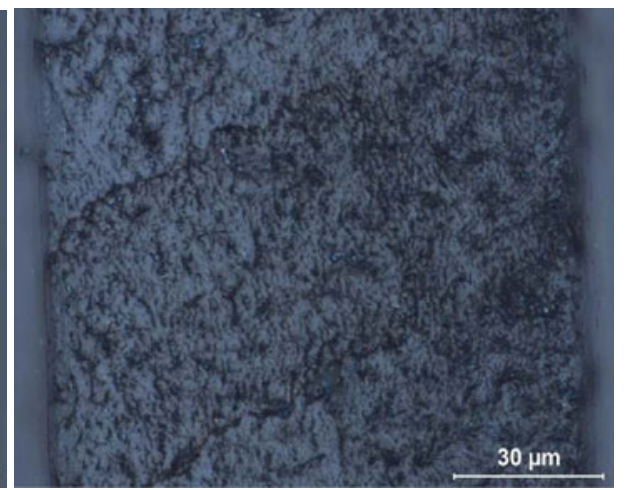

SPEEK $60 / 3 \%$ S-C 1

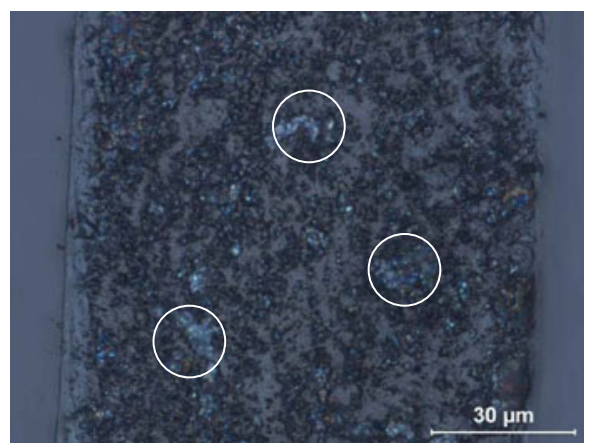

SPEEK 70/3 \% S-C1

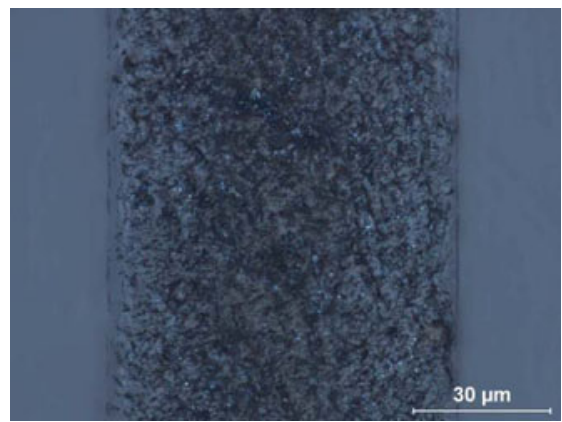

SPEEK60/3 \% S-C2

Figure 7. Optical micrographs of SPEEK-sulfonated carbon black composite membranes with different amounts of sulfonated carbon black particles ( $\mathrm{S}-\mathrm{C} 1$ and $\mathrm{S}-\mathrm{C} 2$ ).

functional groups causing the formation of agglomerates. Moreover, the existence of $\mathrm{SO}_{3} \mathrm{H}$ groups in SPEEK matrix and in carbon black particles have the tendency to create agglomerations due to their hydrophilicity. S-C particles somehow act as plasticizers and therewith, $T_{\mathrm{g}}$ of membrane decreased from 192.2 to $182.4{ }^{\circ} \mathrm{C}$ with the addition of $0.25 \mathrm{wt} \% \mathrm{~S}-\mathrm{C} 1$ to SPEEK60. Agglomerates formed as a result of strong interaction between $\mathrm{S}-\mathrm{C}$ particles and SPEEK matrix could also be prevented by the addition of some additives. However, at fuel cell working conditions, there is a risk of migration of the additives from the membrane and this situation decreases performance of the membrane. 3.3b FTIR studies: FTIR spectra of pristine SPEEK, $\mathrm{S}-$ $\mathrm{C} 1$ and composite membrane with $\mathrm{S}-\mathrm{C} 1$ particles are given in figure 8. Most of the characteristic peaks of carbon black were blocked due to the interference by SPEEK matrix even though in the highest percentages.

3.3c TGA and DSC studies: TGA thermograms of SPEEK60 composite membranes are given in figure 9. Weight loss at the first stage up to $200{ }^{\circ} \mathrm{C}$ was observed due to water absorbed by $-\mathrm{SO}_{3} \mathrm{H}$ groups. It was seen that all composite membranes started to decompose in a rapid manner above $300{ }^{\circ} \mathrm{C}$. The second stage that was located between 300 and $400{ }^{\circ} \mathrm{C}$ can be attributed to the decomposition of 
sulfonic acid groups. The weight loss at $900{ }^{\circ} \mathrm{C}$ was similar to the membranes containing sulfonated and unsulfonated carbon black particles.

DSC results are given in figure 10. A single glass transition temperature $\left(T_{\mathrm{g}}\right)$ was observed for SPEEK polymers at 191.2 and $195.6{ }^{\circ} \mathrm{C}$ for SPEEK60 and SPEEK70, respectively. $T_{\mathrm{g}}$ 's of polymers increased by $10{ }^{\circ} \mathrm{C}$ with the increase of sulfonation degree from 60 to $70 \%$. This was attributed to the incorporation of larger sulfonyl groups that increased
$T_{\mathrm{g}}$ as a result of restrictions on the segmental movements in SPEEK. Addition of 0.25 and $3 \mathrm{wt} \% \mathrm{~S}-\mathrm{C}$ particles to SPEEK60 matrix decreased the glass transition temperature in the ratio of 5 and $7 \%$, respectively. As $T_{\mathrm{g}}$ is sensitive to quite a series of factors, it is suited to be used in microstructural and phase-behavioural studies in polymer blends and composites. In polymer blends, $T_{\mathrm{g}}$ has been used as a parameter to determine thermodynamic component miscibility and with composites it has been proven to be useful in the

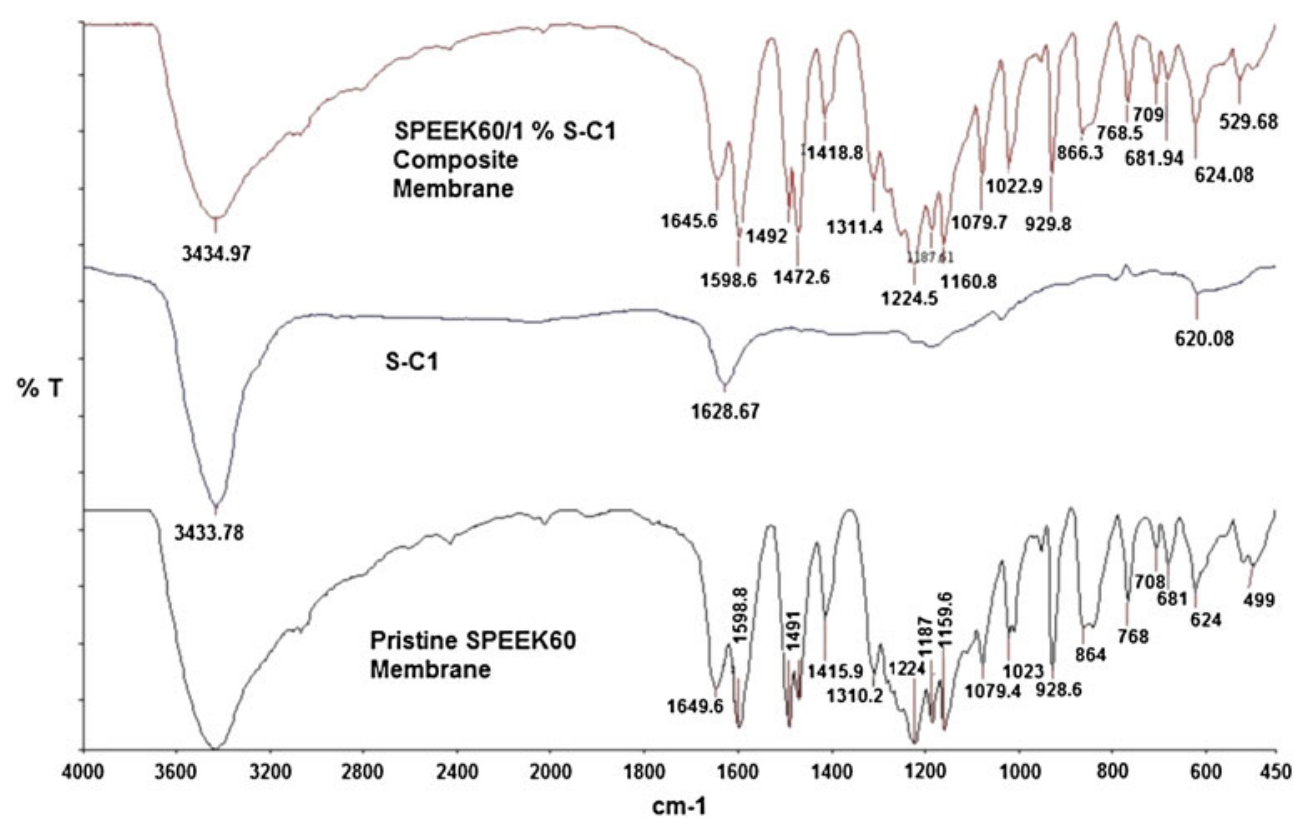

Figure 8. FTIR spectra of pristine SPEEK membrane, sulfonated carbon black samples (S-C1) and SPEEK-sulfonated carbon black composite membranes.

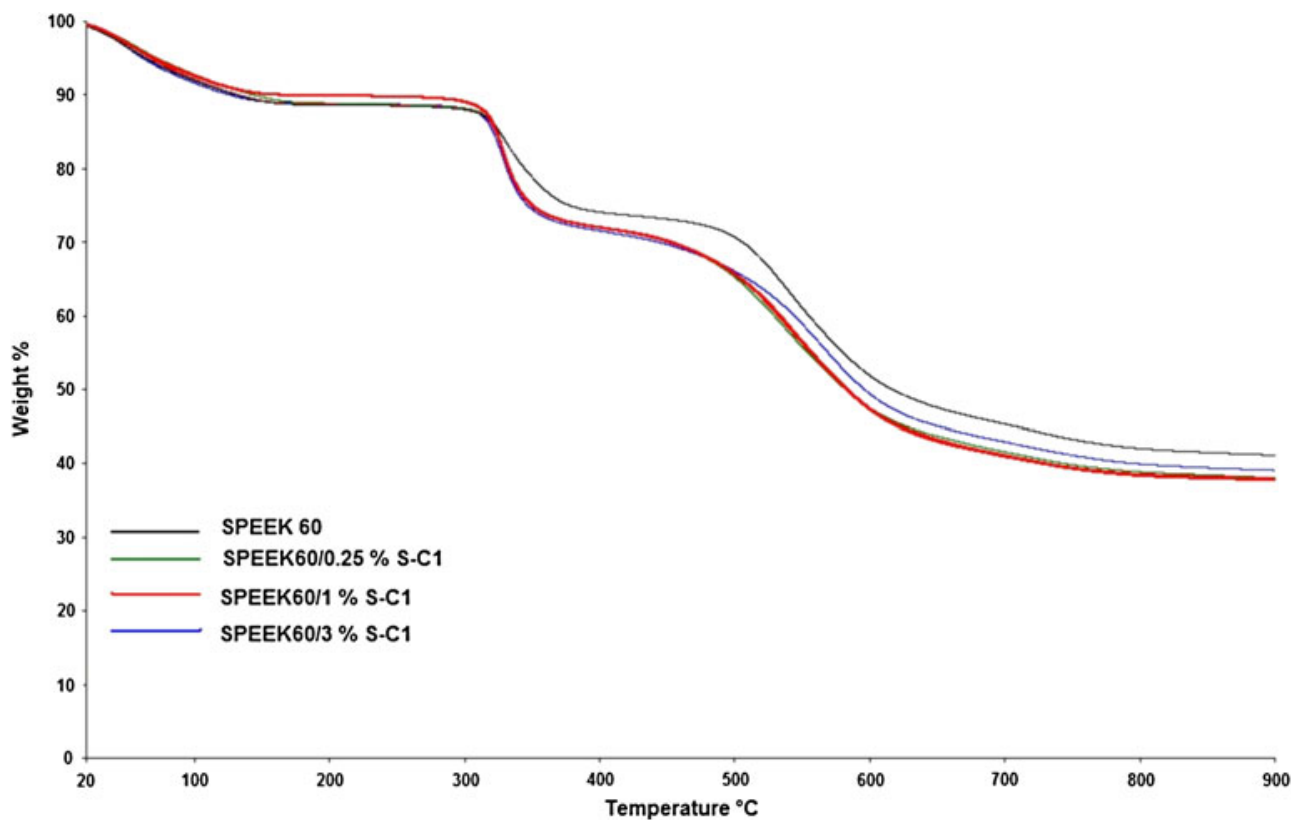

Figure 9. TGA thermograms of SPEEK-sulfonated carbon black (S-C1) composite membranes. 


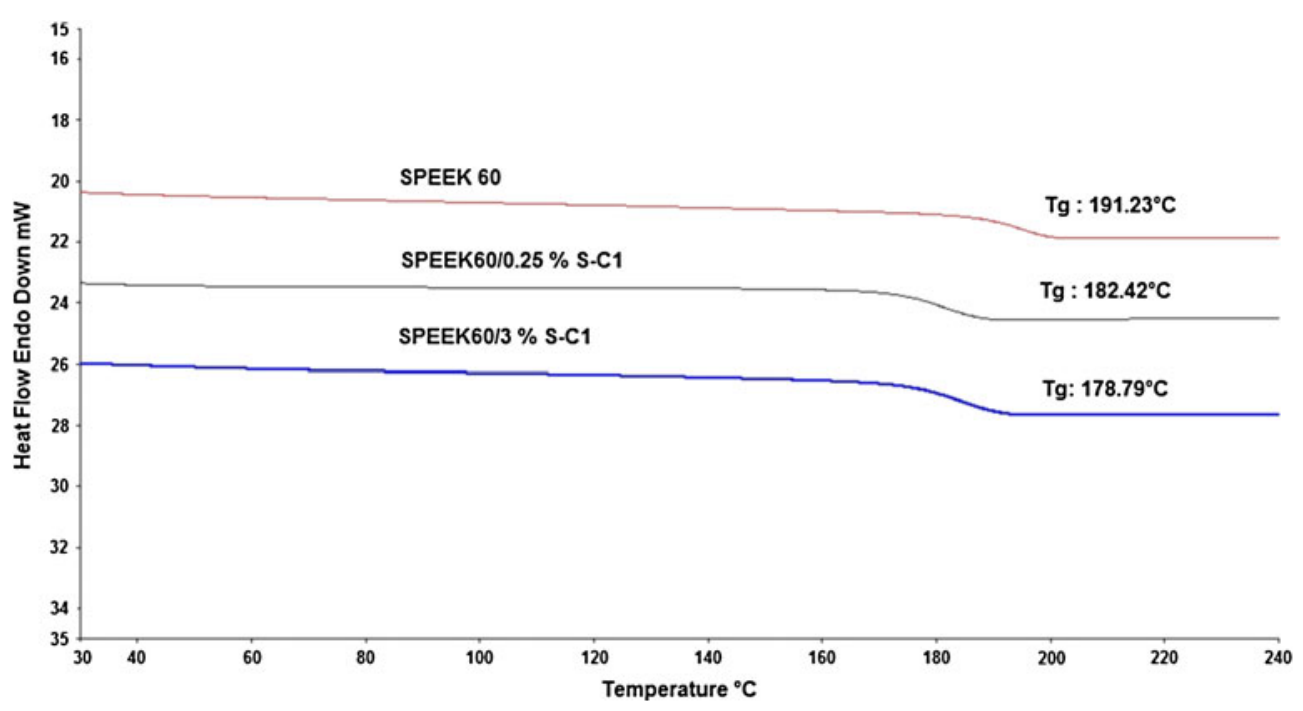

Figure 10. DSC thermograms of SPEEK-sulfonated carbon black (S-C1) composite membranes.

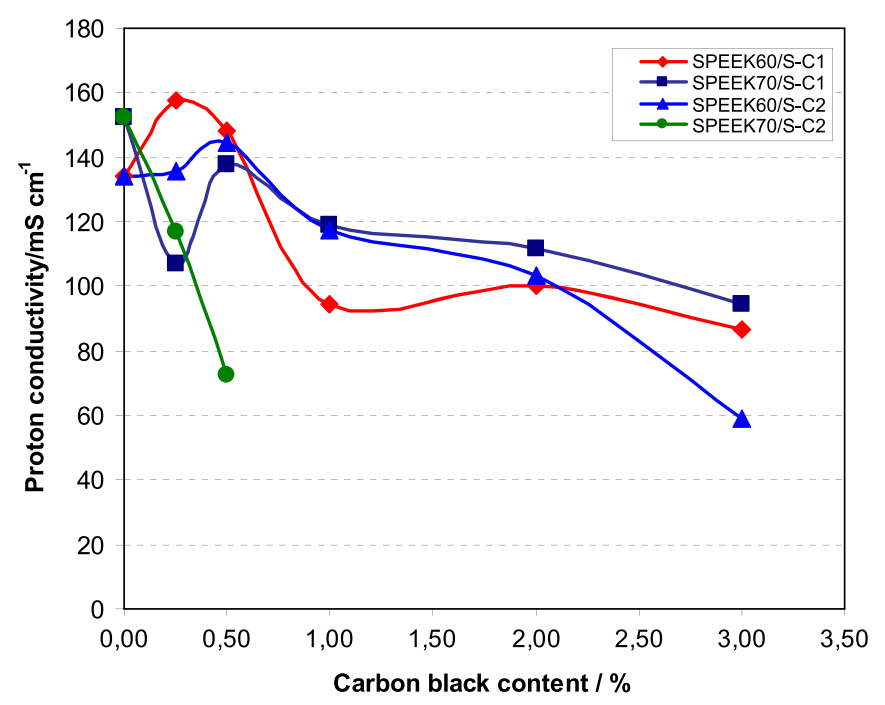

Figure 11. Change of proton conductivity values in terms of sulfonated carbon black content and sulfonation degree of SPEEK.

study of the effects related to filler-polymer adhesion at the interface. In both the cases, $T_{\mathrm{g}}$ shifts towards higher or lower temperatures which allows the related effect to be inferred. In general, the decrease of glass transition temperature in polymer composites is interpreted as an improvement of adhesion at the filler-polymer interface in accordance with the general theory of polymer composites (Rõ̂̂A et al 2000).

3.3d Proton conductivity: Conductivity data for SPEEK/ $\mathrm{S}-\mathrm{C}$ composite membranes, taken at $80{ }^{\circ} \mathrm{C}$ under $100 \% \mathrm{RH}$, as a function of carbon black type and content for two different sulfonation degrees of SPEEK (60 and 70\%) are shown in figure 11. It is seen that the proton conductivity of pristine SPEEK70 has higher than that of pristine SPEEK60 because of the high sulfonation degree as expected. Proton conductivity of SPEEK60/S-C composite membranes increased when the content of S-C particles changed from 0.25 to $0.5 \mathrm{wt} \%$ for both the carbon black particles. Results show that with the increase of S-C1 and S-C2 in SPEEK70 matrix, proton conductivities of the composite membranes decreased due to the agglomeration problem and relative decrease in the amount of SPEEK matrix. The best results came from the membrane with 0.25-0.5 wt $\% \mathrm{~S}-\mathrm{C} 1$ particles in SPEEK 60 , whose conductivities were 157 and $148 \mathrm{mS} / \mathrm{cm}$, respectively. The conductivity of Nafion 117 for comparison was measured as $133 \mathrm{mS} / \mathrm{cm}$ with our test system. Proton conductivity values of SPEEK $/ 0.25 \% \mathrm{~S}-\mathrm{C}$ composite membranes exhibited higher conductivity values $(<133 \mathrm{mS} / \mathrm{cm})$ than Nafion 117. Pristine SPEEK82 membrane also exhibited conductivity $(156.6 \mathrm{mS} / \mathrm{cm})$ higher than that of Nafion $117(133 \mathrm{mS} / \mathrm{cm})$ at $80^{\circ} \mathrm{C}$ and $\mathrm{RH}$ of $100 \%$. Increase in sulfonation degree from 60 to $82 \mathrm{wt} \%$ did not have significant effect on the proton conductivity of the membrane but led to decrease in oxidative stability of the membranes prepared by SPEEK82.

3.3e Water uptake and IEC properties: Water sorption by sulfonated polymers is known to have a profound effect on the membrane conductivity and mechanical stabilities. Figure 12 shows water uptake of the membranes at room temperature. With the increase of sulfonic acid groups, as a result, the water uptake values increased from 27 to $41 \mathrm{wt} \%$ for pristine SPEEK60 and pristine SPEEK70, respectively. It has been reported in the literature (Silva et al 2004) that sulfonation of PEEK polymer results in more hydrophilic character by increasing the protonated sites $\left(-\mathrm{SO}_{3} \mathrm{H}\right)$. In our study, SPEEK70/S-C1 composite membranes indicated higher water uptake values than that of SPEEK60/S-C1 composite membranes as expected. The water uptake values 


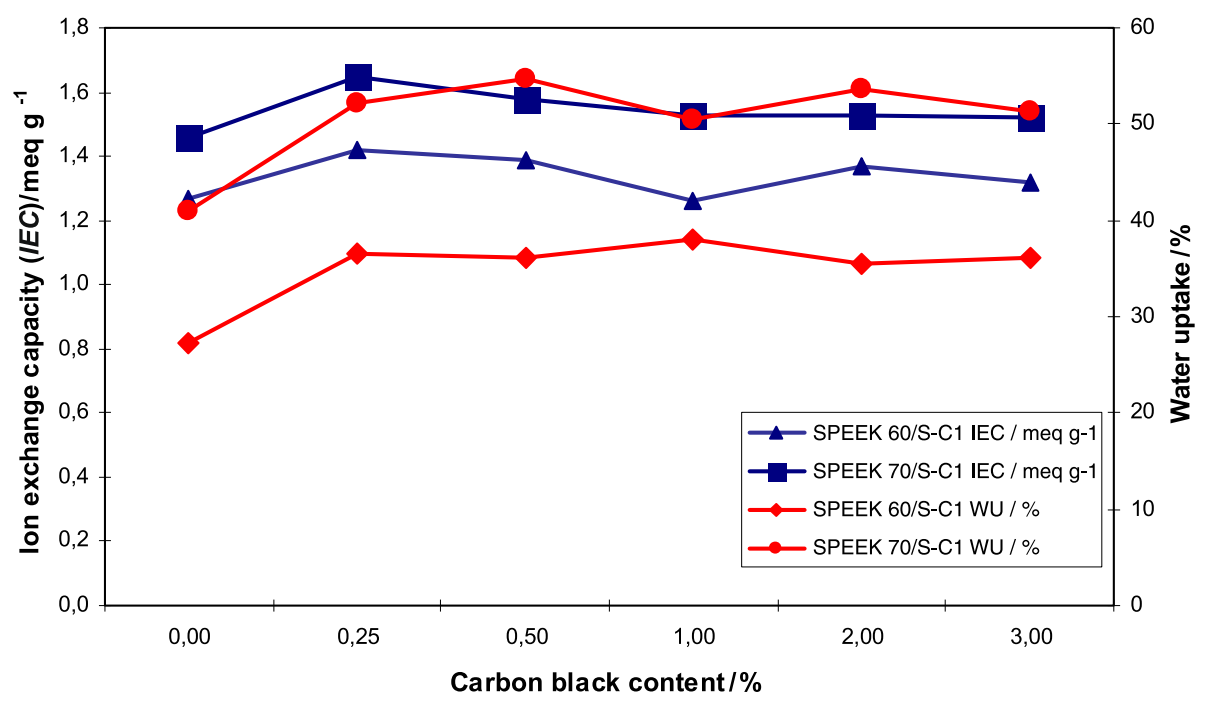

Figure 12. Change of ion exchange capacity (IEC) and water uptake values in terms of sulfonated carbon black (S-C1) content and sulfonation degree of SPEEK.

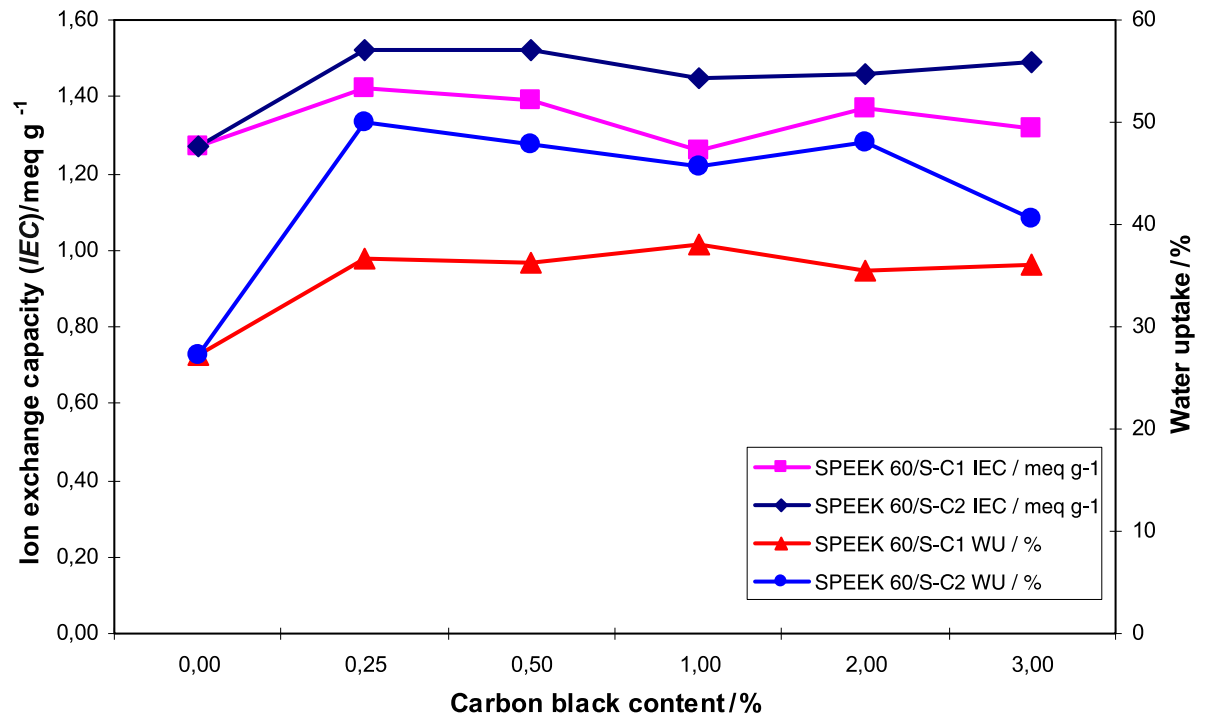

Figure 13. Change of ion exchange capacity (IEC) and water uptake values in terms of sulfonated carbon black content and type.

of SPEEK60 and SPEEK70 composite membranes increased with incorporation of $\mathrm{S}-\mathrm{C} 1$ in the content of $0.25 \mathrm{wt} \%$, however, sulfonated carbon black particles, more than $0.25 \mathrm{wt} \%$ did not cause any change as seen from figure 12. SPEEK60/S-C2 composite membranes also have higher water uptake values than that of SPEEK60/S-C1 composite membranes (figure 13) due to the higher surface area of C2 carbon black sample.

It is seen that the addition of $\mathrm{S}-\mathrm{C} 1$ and $\mathrm{S}-\mathrm{C} 2$ particles into SPEEK polymer in the amount of $0.25 \mathrm{wt} \%$ led to an increased IEC value (figures 12 and 13). However, incorporation of S-C1 particles into SPEEK 70 showed higher IEC values of the membrane than that of SPEEK60/S-C1 composite membranes. The addition of $\mathrm{S}-\mathrm{C} 2$ particles into SPEEK60 showed higher IEC values.

3.3f Chemical stability: Chemical stability of proton exchange membranes is one of the most important factors that affect membrane durability. It is known that the formation of $\mathrm{HO}^{\bullet}$ and $\mathrm{HOO}^{\bullet}$ radicals by the catalytic process during PEMFC operation induces membrane degradation.

Fenton tests of the membranes showed the chemical durability of the membranes in $3 \mathrm{wt} \%$ hydrogen peroxide solution which contained $4 \mathrm{ppm} \mathrm{Fe} \mathrm{Fe}^{+2}$ at $68^{\circ} \mathrm{C}$. In the evaluation of the polymer, when subjected to peroxide radical attack, 
SPEEK60/S-C and SPEEK70/S-C composite membranes broke down completely into pieces after 3 and $1 \mathrm{~h}$, respectively, while $0.3 \%$ weight loss was observed for Nafion 117 after $24 \mathrm{~h}$ at the same test conditions. The addition of $\mathrm{S}-$ $\mathrm{C}$ particles having 0.25 and $3 \mathrm{wt} \%$ decreased the chemical stability.

Pristine and composite SPEEK82 membranes decomposed completely in less than $1 \mathrm{~h}$. Because of the negative properties of SPEEK82 from Fenton test, composite membrane preparation by using SPEEK with DS of $82 \%$ seem not appropriate at this stage since Fenton test predominantly depend on the polymeric matrices than S-C particles. SPEEK70 and 60 composite membranes produced in this study ruptured in 1-3 h, while the rupture time for SPEEK with $40 \%$ DS was recorded for only $1 \mathrm{~h}$ and was measured by Fenton test at the same conditions (Smitha et al 2003).

On the other hand, it was also reported that fuel cell lifetime of membranes based on polybenzimidazoles was over $5000 \mathrm{~h}$, whereas average rupture time of these membranes determined by Fenton test was only $30 \mathrm{~min}$ (Li et al 2004; Gosalawit et al 2008). Since Fenton test exposes membrane to an unrealistic amount of radicals, it acts only as a fast preview test and therefore, a long-term durability test in fuel cell must also be done substantially for determination of the chemical stability of its membrane.

\section{Conclusions}

Commercial grade two carbon black samples, called as Cabot Regal 400R and Cabot Mogul L, were sulfonated with diazonium salt of sulfanilic acid. First, diazonium salt of sulfanilic acid was prepared by the reaction of sulfanalic acid with sodium nitride and then attached onto two different carbon black particles. It was observed that a considerable surface modification was obtained and no big differences found between carbon black samples.

The novel composite polymer membranes based on SPEEK/S-C were obtained using a solution casting method. SPEEK was used with three different DS (60, 70 and 82\%). The best results came from the membrane with $0.25-0.5 \mathrm{wt} \%$ $\mathrm{S}-\mathrm{C} 1$ in SPEEK60, whose conductivities were 157 and $148 \mathrm{mS} / \mathrm{cm}$, respectively. The addition of S-C1 and S-C2 particles into SPEEK polymers having $0.25 \mathrm{wt} \%$ led to increased IEC value. The water uptake values of SPEEK60 and SPEEK70 composite membranes increased with the incorporation of S-C1 in the content of $0.25 \mathrm{wt} \%$, however, $\mathrm{S}-\mathrm{C}$ particles more than $0.25 \mathrm{wt} \%$ did not cause any change due to the agglomeration problem and at the same time, relative decrease in SPEEK content as well. The incorporation of
S-C1 and S-C2 particles above $0.25 \%$ also caused decrease in the chemical stability.

The composite membranes produced in this study using carbon blacks are found to be appropriate for fuel cell applications.

\section{Acknowledgements}

Turk Demirdokum Fabrikaları A.Ş. is acknowledged for their financial support. The authors thank Dr Elif Ünveren, Handan Karakale, Nevin Bekir, Zekayi Korlu and Mustafa Candemir for valuable technical assistance in the laboratory experiments. Operation of SEM was possible with the help of Orhan İpek and Cem Berk.

\section{References}

Barroso-Bujans F, Verdejo R, Arroyo M, Lopez-Gonzalez M M, Riande E and Lopez-Manchado M A 2008 Macromol. Rapid Commun. 29234

Drioli E, Regina A, Casciola M, Oliveti A, Trotta F and Massari T 2004 J. Membr. Sci. 228139

Fu T, Cui Z, Zhong S, Shi Y, Zhao C, Zhang G et al 2008 J. Power Sources 18532

Girard S A, Solal F, Fabre B, Alibart F and Godet C 2006 J. NonCryst. Solids 3522011

Gosalawit R, Chirachanchai S, Shishatskiy S and Nunes S P 2008 J. Membr. Sci. $\mathbf{3 2 3} 337$

Herring A M 2006 J. Macromol. Sci. Polym. Rev. 46245

Joo S H et al 2008 J. Power Sources 18063

Kannan R, Kakade B A and Pillai V K 2008 Angew Chem. In. Ed. 472653

Kerres A, Meier U F and Haring T 1999 Solid State Ionics 125243

Lakshmi N, Rajalakshmi N and Dhathathreyan K S 2006 J. Phys. D: Appl. Phys. 392785

Li Q, He R, Jensen J Q and Bjerrum N J 2004 Fuel Cells 4159

Liu Y H, Yi B, Shao Z G, Xing D and Zhang H 2006 Electrochem. Solid-State Lett. 9 A-356

RõÂo C D, Ojed M C and Acosta J L 2000 Eur. Polym. J. 361687

Rositani F, Antonucci P L, Minutoli M and Giordano N 1987 Carbon 25325

Silva V, Ruffmann B, Silva H, Mendes A, Maderia M and Nunes S 2004 Mater. Sci. Forum 455587

Smitha B, Sridhar S and Khan A A 2003 J. Membr. Sci. 22563

Thomassin J M, Kollar J, Caldarella G, Germain A, Jerome R and Detrembleur C 2007 J. Membr. Sci. 303252

Wang L, Xing D M, Zhang H M, Yu H M, Liu Y H and Yi B L 2008 J. Power Sources 176270

Xing P, Robertson G P, Guiver M D, Mikhailenko S D, Wang K and Kaliaguine S 2004 J. Membr. Sci. 22995

Zaidi S M J 2003 Arabian J. Sci. Eng. 2883

Zhang L and Mukerjee S 2006 J. Electrochem. Soc. 153 A1062 